\title{
Ageing and duodenal morphometry
}

\author{
P S Lipski, M K Bennett, P J Kelly, O F W James
}

\begin{abstract}
Small bowel morphometry was studied in 25 subjects under the age of 70 years and 22 over the age of 70 . There was no evidence of malabsorption or malnutrition in either group. Two distal duodenal endoscopic biopsy specimens were examined morphometrically. There were no significant correlations between age and areas of duodenal surface epithelium, crypts and lamina propria, heights of villi and surface epithelium, depth of crypts, crypt to villus ratio, number of intraepithelial lymphocytes, duodenal architecture, enterocytes, brush border and Brunner glands. Contrary to previous reports there was no evidence for a significant effect of age on proximal small bowel morphometry.
\end{abstract}

Small bowel malabsorption is an important cause of malnutrition and morbidity in the elderly. ${ }^{12}$ Previous studies in rats ${ }^{3}$ and humans ${ }^{45}$ have reported that villus height or surface area is reduced with age in the proximal small bowel, and it has been hypothesised that this could lead to decreased absorption in old age. However, there is very little information in humans on which to base this claim. The aim of the present study was to assess the effect of ageing on small bowel morphology by examining distal duodenal biopsy specimens from adults across a wide age range without evidence of malabsorption or malnutrition.

Department of

Geriatric Medicine, University of Newcastle upon Tyne P S Lipski

O F W James

Department of Histopathology, Freeman Hospital, Newcastle upon Tyne M K Bennett

Department of Medical Statistics, University of Newcastle upon Tyne P J Kelly

Correspondence to: Professor O F W James, University of Newcastle upon Tyne, Department of Medicine (Geriatrics), Floor 4, William Leech Building, The Medical
School, Framlington Place, Newcastle upon Tyne NE2 4HH.

Accepted for publication 18 September 1991

Methods

Subjects were randomly selected from a routine outpatient endoscopy list at the Freeman Hospital, Newcastle upon Tyne. These patients were attending for investigation or follow up of dyspepsia, previous gastric ulcer disease, or unexplained iron deficiency anaemia. Subjects who had known malignancy, active gastrointestinal disease other than previous gastric ulceration, or conditions predisposing them to malabsorption or malnutrition were excluded from the study. Patients with conditions which may be associated with abnormal proximal small bowel mucosal appearance, such as rheumatoid arthritis, previous gastric surgery, congestive heart failure, inflammatory bowel disease, extensive dermatosis, pancreatic disease and immune deficiency were also excluded. All the subjects had normal anthropometric indices for $\operatorname{age}^{67}$ and had normal blood count, blood film, serum biochemistry, and no duodenal disease present on endoscopic inspection, or on conventional duodenal histology.

This study was approved by the Newcastle upon Tyne joint ethics committee, and written informed consent was obtained from all subjects.

Two endoscopic duodenal biopsy specimens (Keymed Jumbo Forceps) were obtained from the distal second to third part of duodenum, fixed in formalin, stained with haematoxylin and eosin, and examined histologically and morphometrically ${ }^{8}$ by a single experienced histopathologist (MKB) who was unaware of the patient's age. Morphometric measurements included areas of the duodenal surface epithelium, crypts and lamina propria, heights of the villi and surface epithelium, crypt depth and intraepithelial lymphocyte count per 100 enterocytes. Duodenal architecture was coded as either normal, partial villus atrophy (PVA), or subtotal villus atrophy. Enterocytes were described as either normal or megaloblastic; the brush border was either normal or indistinct, and Brunner glands were either normal or abnormal.

Quantitative assessment of the duodenal biopsy specimens used only well orientated sections. A summation average graph was plotted to calculate the optimal number of points to be counted for the area fractions. For each sample using the Mertz graticule (Graticules Ltd, Tunbridge Wells, Kent) 1000 points were counted to estimate the relative surface, crypt, and lamina propria area fraction. The final magnification used was $\times 250$.

Villus height and crypt depth were measured using an eye-piece graticule (NE7, Graticules Ltd) which was calibrated and used at a final magnification of $\times 160$. Using cells from the middle of the villus, enterocyte height was measured using a total magnification of $\times 1000$. A total of 50 cells per sample were counted. Intraepithelial lymphocyte numbers were counted using an oil immersion lens (total magnification $\times 1000$ ). Five hundred enterocytes and lymphocytes were counted from the upper two thirds of the villus. The number of lymphocytes was then expressed as the number of intraepithelial lymphocytes per 100 enterocytes.

The data were not normally distributed so non-parametric statistics were used. Spearman's rank correlation coefficient was 
Figure 1 Scatterplot of area of surface epithelium (\%) vage (years).

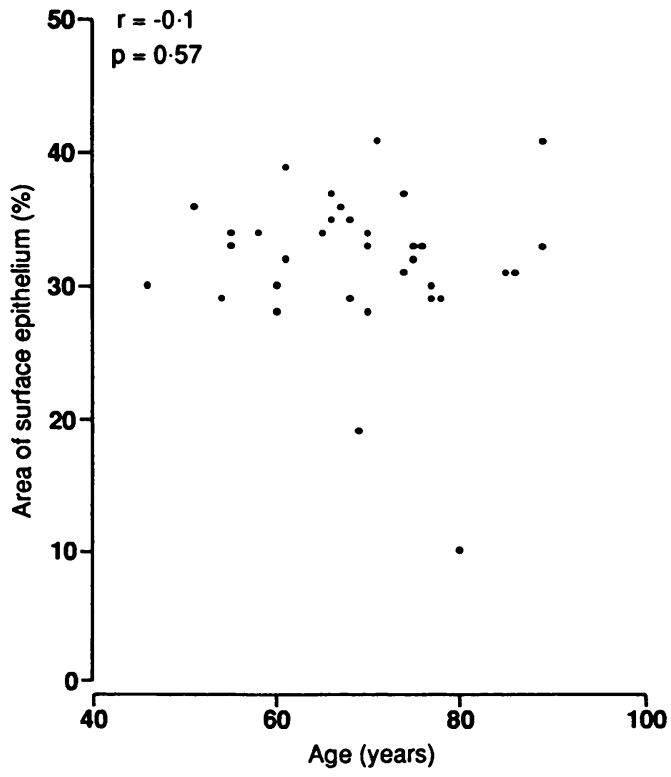

used to assess the correlation between age $v$ morphometric indices as continuous variables. The data were then split into two age groups: over and under 70 years and analysed using the $\chi^{2}$ and Mann-Whitney $U$ test, with approximate $95 \%$ confidence intervals for the difference in medians obtained via the Minitab statistical package (Minitab Inc, State College, Pennysylvania USA).

\section{Results}

Thirty nine subjects were studied, mean age $69 \cdot 1$ years, range 46 to 89, SD $10 \cdot 8$ years. Male to female ratio was 19:20. There were no significant correlations between age and area of duodenal surface epithelium, area of crypts, area of lamina propria, heights of surface epithelium and villi, crypt depth, crypt to villus ratio, and number of intraepithelial lymphocytes (table 1). Medians, interquartile ranges, and ranges for morphometric indices for those subjects above and below 70 years are given in table 2 . Although the median area of duodenal surface epithelium, villus and epithelial height, crypt depth and crypt to villus ratio were slightly reduced in subjects over the age of 70 years, the differences did not approach significance in any of these variables. Median area of the lamina propria and intraepithelial lymphocyte count per 100 enterocytes were greater in those subjects over the age of 70 years, but these differences were again not significant. There was no change in duodenal

Table 1 Age v morphometry

\begin{tabular}{llll}
\hline & $\begin{array}{l}\text { Number } \\
\text { of cases }\end{array}$ & $r^{\star}$ & p.Value \\
\hline Area epithelium $(\%)$ & 37 & -0.1 & 0.57 \\
Area crypt $(\%)$ & 37 & 0.05 & 0.76 \\
Area lamina propria (\%) & 37 & 0.008 & 0.97 \\
Villus height $(\mu \mathrm{m})$ & 35 & -0.27 & 0.11 \\
Crypt death $(\mu \mathrm{m})$ & 35 & -0.12 & 0.50 \\
Epithelial height $(\mu \mathrm{m})$ & 38 & -0.15 & 0.36 \\
CV ratio & 39 & -0.31 & 0.06 \\
Lymphocyte count & 38 & 0.04 & 0.80 \\
\hline
\end{tabular}

^Spcarman's rank correlation coefficient.

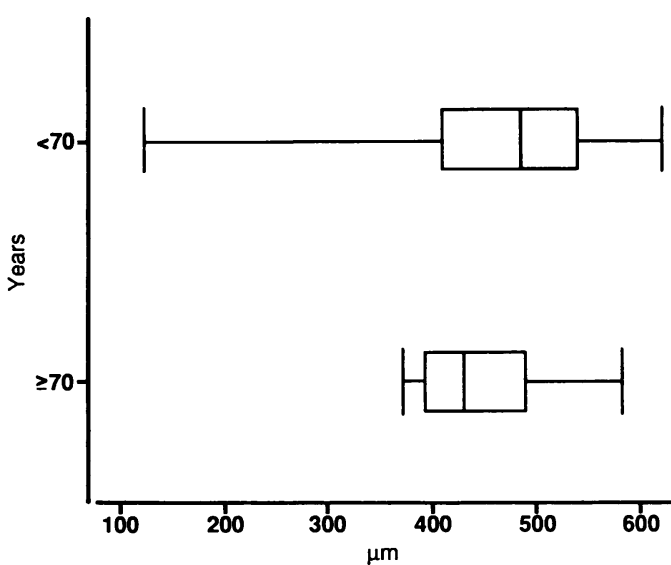

Figure 2 Boxplots of villus height for the two age groups.

architecture, enterocytes, brush border or Brunner glands with age.

\section{Discussion}

It is now almost impossible within ethical constraints to obtain small bowel biopsy specimens from normal healthy elderly subjects with no past or present symptoms of upper gastrointestinal disease. We selected individuals who either had abdominal symptoms justifying endoscopy who were found to have no abnormalities on endoscopic inspection or routine histology, and to have none of the exclusion criteria listed, or those who had had previous gastric ulcer while undergoing a checkup endoscopy, but which was found to have healed with appropriate medication, or were no longer taking medication. We feel that this group may appropriately be considered as "normal".

Webster and Leeming ${ }^{4}$ reported that the proximal jejunal villi of 16 geriatric patients undergoing a course of rehabilitation were broader and shorter than those of 32 young subjects. However, many of their elderly patients were malnourished and small bowel malabsorption was not specifically excluded. The mean villus height of their geriatric patients was $371 \mu \mathrm{m}$ which was significantly lower than the weighted mean $(471 \mu \mathrm{m})$ of previously published controls, but similar to the young controls of another study. ${ }^{9}$ The mean villus height for subjects greater and less than 70 years in our study was lower than the control groups from Webster and Leeming's paper ${ }^{4}$ but greater than that reported by Penna et al. ${ }^{9}$ The crypt depth and CV ratio were greater, while epithelial height in our study was less than the value for seven healthy controls reported by Penna et al. ${ }^{9}$ We know of no detailed studies in the elderly with which to compare our morphometric findings, but epithelial height from the study by Corazza et al ${ }^{10}$ was slightly greater than our value (30.1 (SD 1.2) $v 27.9(2.1) ; \mathrm{p}<0.001)$. Warren et $a l^{5}$ reported highly significant reductions in mucosal surface area in 10 well nourished elderly patients aged $60-73$ years compared with 10 controls aged 16-30. However, the 
Table 2 Morphometry by age group

\begin{tabular}{|c|c|c|c|c|c|c|}
\hline & $N=$ & Minimum & Lower quartile & Median & Upper quartile & Maximum \\
\hline $\begin{array}{l}\text { Area epithelium }(\%)<70 \mathrm{y} \\
\geq 70 \mathrm{y}\end{array}$ & $\begin{array}{l}18 \\
19\end{array}$ & $\begin{array}{l}19 \cdot 0 \\
28 \cdot 0\end{array}$ & $\begin{array}{l}29 \cdot 8 \\
30 \cdot 0\end{array}$ & $\begin{array}{l}34 \cdot 0 \\
32 \cdot 0\end{array}$ & $\begin{array}{l}35 \cdot 0 \\
33 \cdot 0\end{array}$ & $\begin{array}{l}39 \cdot 0 \\
41 \cdot 0\end{array}$ \\
\hline $\begin{array}{l}\text { Area crypt }(\%)<70 \text { y } \\
\geq 70 \mathrm{y}\end{array}$ & $\begin{array}{l}18 \\
19\end{array}$ & $\begin{array}{l}15 \cdot 0 \\
13 \cdot 0\end{array}$ & $\begin{array}{l}19 \cdot 0 \\
19 \cdot 0\end{array}$ & $\begin{array}{l}20 \cdot 0 \\
20 \cdot 0\end{array}$ & $\begin{array}{l}19 \cdot 0 \\
19 \cdot 0\end{array}$ & $\begin{array}{l}22 \cdot 3 \\
22 \cdot 0\end{array}$ \\
\hline $\begin{array}{l}\text { Area } L P(\%)<70 y \\
\geq 70 y\end{array}$ & $\begin{array}{l}19 \\
20\end{array}$ & $\begin{array}{l}42 \cdot 0 \\
41 \cdot 0\end{array}$ & $\begin{array}{l}44 \cdot 0 \\
46 \cdot 0\end{array}$ & $\begin{array}{l}47 \cdot 0 \\
47 \cdot 3\end{array}$ & $\begin{array}{l}50 \cdot 0 \\
49 \cdot 0\end{array}$ & $\begin{array}{l}53 \cdot 0 \\
53 \cdot 1\end{array}$ \\
\hline $\begin{array}{l}\text { Villus height }(\mu \mathrm{m})<70 \mathrm{y} \\
\geq 70 \mathrm{y}\end{array}$ & $\begin{array}{l}18 \\
17\end{array}$ & $\begin{array}{l}125 \cdot 0 \\
374 \cdot 0\end{array}$ & $\begin{array}{l}421 \cdot 7 \\
394 \cdot 5\end{array}$ & $\begin{array}{l}487 \cdot 0 \\
432 \cdot 0\end{array}$ & $\begin{array}{l}541 \cdot 5 \\
490 \cdot 5\end{array}$ & $\begin{array}{l}623 \cdot 0 \\
585 \cdot 0\end{array}$ \\
\hline $\begin{array}{l}\text { Crypt depth }(\mu \mathrm{m})<70 \text { y } \\
\geq 70 y\end{array}$ & $\begin{array}{l}18 \\
17\end{array}$ & $\begin{array}{l}122 \cdot 0 \\
110 \cdot 0\end{array}$ & $\begin{array}{l}136 \cdot 2 \\
125 \cdot 5\end{array}$ & $\begin{array}{l}161 \cdot 0 \\
142 \cdot 0\end{array}$ & $\begin{array}{l}196 \cdot 5 \\
165 \cdot 5\end{array}$ & $\begin{array}{l}548 \cdot 0 \\
188 \cdot 0\end{array}$ \\
\hline $\begin{array}{l}\text { Epithelial height }(\mu \mathrm{m})<70 \mathrm{y} \\
\geq 70 \mathrm{y}\end{array}$ & $\begin{array}{l}19 \\
19\end{array}$ & $\begin{array}{l}24 \cdot 9 \\
24 \cdot 8\end{array}$ & $\begin{array}{l}27 \cdot 0 \\
26 \cdot 0\end{array}$ & $\begin{array}{l}28 \cdot 7 \\
27 \cdot 9\end{array}$ & $\begin{array}{l}30 \cdot 9 \\
29 \cdot 2\end{array}$ & $\begin{array}{l}32 \cdot 8 \\
31 \cdot 5\end{array}$ \\
\hline $\begin{array}{l}\mathrm{CV} \text { ratio }<70 \mathrm{y} \\
\geq 70 \mathrm{y}\end{array}$ & $\begin{array}{l}18 \\
17\end{array}$ & $\begin{array}{l}2 \cdot 3 \\
2 \cdot 5\end{array}$ & $\begin{array}{l}3 \cdot 1 \\
2 \cdot 9\end{array}$ & $\begin{array}{l}3 \cdot 2 \\
3 \cdot 1\end{array}$ & $\begin{array}{l}3 \cdot 5 \\
3 \cdot 4\end{array}$ & $\begin{array}{l}4 \cdot 0 \\
3 \cdot 6\end{array}$ \\
\hline $\begin{array}{l}\text { Lymphocyte count }<70 \text { y } \\
\geq 70 \text { y }\end{array}$ & $\begin{array}{l}19 \\
19\end{array}$ & $\begin{array}{l}6 \cdot 0 \\
5 \cdot 0\end{array}$ & $\begin{array}{l}8 \cdot 0 \\
8 \cdot 0\end{array}$ & $\begin{array}{l}11 \cdot 3 \\
11.9\end{array}$ & $\begin{array}{l}15 \cdot 0 \\
16 \cdot 0\end{array}$ & $\begin{array}{l}21 \cdot 0 \\
20 \cdot 0\end{array}$ \\
\hline
\end{tabular}

number of subjects studied and the age ranges were too restrictive to make predictions about the effects of ageing. Their other findings that mean villus height, enterocyte height, and intra-epithelial lymphocyte counts were not significantly different in young and old subjects were similar to ours. The study by Corazza et $a l,{ }^{10}$ found that mean surface to volume ratios and enterocyte height in 16 well nourished elderly patients were not significantly different from 22 younger controls.

In summary, we did not find any significant difference in duodenal morphometry with age. Thus there was no evidence to support the hypothesis that possibly impaired absorption in normal old age may relate to morphometric changes in the upper small bowel mucosa.

We thank Drs Ian Turner and Alison Brind for the endoscopic biopsy specimens and "Research into Ageing" for their generous grant.

1 Montgomery RD, Haeney MR, Ross IN, et al. The ageing gut: A study of intestinal absorption in relation to nutrition in the elderly. $Q J$ Med 1978;47:197-211.

2 McEvoy A, Dutton J, James OFW. Bacterial contamination of the small bowel is an important cause of occult malabsorption in the elderly. Br Med J 1983;287:789-93.

3 Jakab L, Penzes L. Relationship between glucose absorption and villus height in ageing. Experientia 1981;37:740-2

Webster SGP, Leeming JT. The appearance of the smal bowel mucosa in old age. Age Ageing 1975;4:168-74.

5 Warren PM, Pepperman MA, Montgomery RD. Age changes in small-intestinal mucosa. Lancet 1978;ii: changes

6 McEvoy AW, James OFW. Anthropometric indices in normal elderly subjects. Age Ageing 1982;11:97-100.

7 Jelliffe DB. Assessment of nutritional status of the community. Geneva: WHO, 1966.

8 Aherne WA, Dunnill MS, eds. Morphometry. London Edward Arnold, 1982.

9 Penna FJ, Hill ID, Kingston D, Robertson K, Slavin G Shiner $M$. Jejunal mucosal morphometry in children with and without gut symptoms and in normal adults. $J$ Clin Pathol 1981;34:386-92.

10 Corazza GR, Frazzoni M, Gatto MRA, Gasbarrini G. Ageing and small bowel mucosa: a morphometric study. Gerontol 1986;32:60-5.
Department of Pathology, Rambam Medical Center, and Technion-Faculty of Medicine, Haifa, Israel O Ben-Izhak C Lichtig

Correspondence to: Dr O Ben-Izhak

Accepted for publication 19 September 1991

\begin{abstract}
A post mortem examination of a 70 year old man, who died three years after a poorly differentiated adenocarcinoma of prostate had been diagnosed, showed widespread signet-ring cell carcinoma, with an associated linitis plastica. The signet-ring cells stained positively with prostatic specific antigen and with prostatic specific acid phosphatase, but failed to react with mucopolysaccharide staining. The electron microscopic appearance of the signet-ring cell tumour was due to the presence of large cytoplasmic vacuoles.
\end{abstract}

This case emphasises the possibility that cases of metastatic signet-ring cell carcinoma may be prostatic in origin. This can be confirmed by specific immunohistochemical studies.

Prostatic adenocarcinoma composed of signetring cells is very rare, ${ }^{12}$ and reports of these as metastases are even less common. ${ }^{2}$

Metastases of any kind to the stomach are rare, ${ }^{3}$ and when they present as linitis plastica, they usually arise from lobular carcinoma of the breast. ${ }^{4}$

We describe a case of dissemined signet-ring cell carcinoma that produced a linitis plastica 